\title{
The Biological Significance of Glycyrrhizin- and Glycyrrhetinic Acid Derivative-Induced Selective Phosphorylation of Histones H2A and H2B by A-kinase In Vitro
}

\author{
Fazel Shamsa*, Takeshi Iwasa, Hitoshi Saito, \\ Nobuyuki Nagata $†$ and Kenzo Ohtsuki \\ Laboratory of Genetical Biochemistry, Department of \\ Bioscience, Kitasato University School of Hygienic Sciences, \\ Sagamihara 228, and $\dagger$ Research Laboratories of \\ Minophagen Pharmaceutical Co., Ltd., Zama 228
}

\begin{abstract}
Shamsa, F., Iwasa, T., Saito, H., Nagata, N. and Ohtsuki, K. The Biological Significance of Glycyrrhizin- and Glycyrrhetinic Acid Derivative-Induced Selective Phosphorylation of Histones H2A and H2B by A-kinase In Vitro. Tohoku J. Exp. Med., 1994, 172 (2), 123-132 - Histones H2A and H2B were found to be glycyrrhizin (GL)-binding proteins, because (i) the two histones H2A-H2B pairs were isolated selectively from the crude histone preparations of calf thymus by means of GL-affinity column chromatography (HPLC); (ii) phosphorylation of these two histones by A-kinase was remarkably stimulated by native GL or oGA (a derivative of glycyrrhetinic acid) at $20 \mu \mathrm{M}$; and (iii) in the crude histone preparations of calf thymus, these two histones were selectively phosphorylated by A-kinase in the presence of both dsDNA and $20 \mu \mathrm{M}$ oGA or $20 \mu \mathrm{M}$ GL. The provided data suggest that the GL-induced selective phosphorylation of histones $\mathrm{H} 2 \mathrm{~A}$ and $\mathrm{H} 2 \mathrm{~B}$ by A-kinase may be implicated in the transcriptional activation involved in the biological activities of the drug.—-glycyrrhizin; glycyrrhetinic acid derivative; A-kinase; histone phosphorylation; antiinflammatory effect
\end{abstract}

Glycyrrhizin (GL), a molecule of glycyrrhetinic acid (GA) and two molecules of glucuronic acid, is one of the aqueous extracts from roots of the licorice, Glycyrrhizin radix, and is known for its anti-inflammatory property in Chinese

Received November 12, 1993; revision accepted for publication December 27, 1993.

*Present address: Department of Pharmaceutical Chemistry, College of Pharmacy, Tehran University, Tehran, Iran.

Address for reprints: Kenzo Ohtsuki, Laboratory of Genetical Biochemistry, Department of Bioscience, Kitasato University School of Hygienic Sciences, Sagamihara 228, Japan.

Abbreviations: GL, glycyrrhizin; GA, glycyrrhetinic acid; oGA, olean-11, 13 (18)diene-3 $\beta$, 30-diol $3 \beta$, 30-di-o-hemiphthalate $2 \mathrm{Na}$; A-kinase, cAMP-dependent protein kinase; CK-II, casein kinase II; dsDNA, double-stranded DNA; IFN $\gamma, \gamma$-type interferon; SDS-PAGE, sodium dodecylsulfate polyacrylamide gel electrophoresis; HPLC, high performance liquid chromatography. 
medicine (Finney and Somers 1959; Dargan and Subak-Sharpe 1985). It has an anti-viral activity in several RNA viruses (Pompei et al. 1979), including human immunodeficiency type I virus (HIV-I) (Ito et al. 1987), and an inducing activity of $\gamma$-type interferon (IFN $\gamma$ ) (Abe et al. 1982). Although recently it has also been reported that GL induces selectively extrathymic $\mathrm{T}$ cells in mouse liver at its clinical dose (Kimura et al. 1992), the biochemical mechanisms involved in these biological effects of GL remain to be elucidated. In the metabolism of cortisol in rat, GA inhibits both hepatic $\Delta^{\prime}-5$-reductase and $11 \beta$-hydroxysteroid dehydrogenase in a dose-dependent manner and this inhibition results in the decrease of conversion of cortisone, dihydrocortisol and tetrahydrocortisol from cortisol (Kojima et al. 1990).

Recently, we reported that (i) phosphorylation of lipocortin I by A-kinase is highly stimulated at the GL concentrations between $10 \mu \mathrm{M}$ and $20 \mu \mathrm{M}$ (Shamsa et al. 1991; Ohtsuki et al. 1992); (ii) one (olean-11,13 (18)-diene-3 $\beta$, 30-diol $3 \beta$, 30-di-o-hemiphthalate $2 \mathrm{Na}$, oGA) of the GA derivatives is the most effective compound for stimulation of the activity of A-kinase (Shamsa et al. 1991; Ohtsuki et al. 1992); and (iii) lipocortin I was identified as one of GL-binding proteins (Ishikawa et al. 1990; Ohtsuki et al. 1992). On the other hand, recent studies (Felsenfeld 1992; Grunstein 1992) on the physiological functions of histones revealed that these DNA-binding basic proteins are vital participants in gene regulation (Felsenfeld 1992). Therefore, the present study has been undertaken (i) to characterize histones as GL-binding polypeptides, which may function as mediators involved in the biological activities of GL; and (ii) to investigate mainly the biochemical effects of oGA on the phosphorylation of histones by A-kinase in vitro. Here, we describe (i) selective separation of histones (H2A and $\mathrm{H} 2 \mathrm{~B}$ ) as a $\mathrm{H} 2 \mathrm{~A}-\mathrm{H} 2 \mathrm{~B}$ pair from the crude histone preparations by means of GL-affinity column chromatography; (ii) the stimulatory and inhibitory effects of GL and oGA on the phosphorylation of histones by A-kinase; and (iii) the selective phosphorylation of histones $\mathrm{H} 2 \mathrm{~A}$ and $\mathrm{H} 2 \mathrm{~B}$ by A-kinase in the presence of both dsDNA and oGA or GL. From the results of these experiments, we can propose that the GL- and oGA-induced stimulation of the A-kinase catalyzed selective phosphorylation of histones $\mathrm{H} 2 \mathrm{~A}$ and $\mathrm{H} 2 \mathrm{~B}$ may be implicated in the transcriptional activation involved in the anti-inflammatory effect of the drug.

\section{Materials and Methods}

\section{$G L$ and $o G A$}

Native GL and oGA (olean-11, 13(18)-diene-3 $\beta, 30$-diol 3 $\beta$, 30-di-o-hemiphthalate 2Na) (Fig. 1) were kindly supplied by Minophagen Pharmaceutical Co., Ltd. (Tokyo). A 10 mM preparation of these two compounds in $1 \%$ dimethylsulphonyl sulphate (DEMSO) was diluted with sterilized water. These drug preparations were freshly made for each experiment and used immediately. 
(a) GL

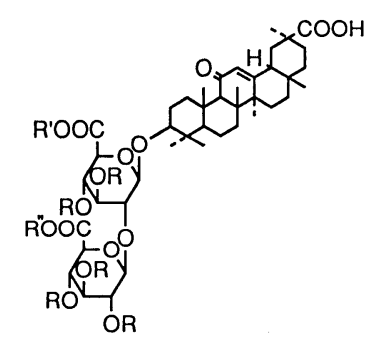

$\mathbf{R}=\mathbf{R}^{\prime}=\mathbf{R}^{\prime \prime} \quad \mathbf{H}$ (b) oGA

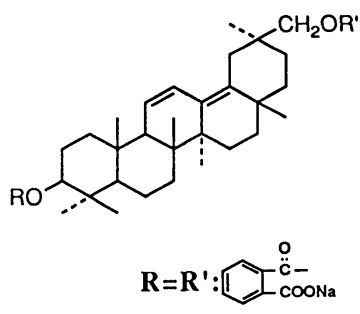

Fig. 1. The chemical structures of GL (a) and oGA(b).

\section{Histones}

Whole histone preparations (types II-A and III-S) of calf thymus were obtained from Sigma Chemical Corp. (St. Louis, MO, USA). Other crude histone fractions from rat liver were prepared by the modified method described originally by Strickland et al. (1980). Purified histones ( $\mathrm{H} 1, \mathrm{H} 2 \mathrm{~A}, \mathrm{H} 2 \mathrm{~B}, \mathrm{H} 3$ and $\mathrm{H} 4$ ) of calf thymus were obtained from Boehringer-Mannheim Biochemicals (Mannheim, Germany).

\section{GL-affinity column}

A GL-affinity column was prepared as described originally by Nakamura et al. (1990) using Tresyl-5PW (packing gel for HPLC, Tosoh Mfg. Co., Ltd., Tokyo) and $\mathrm{N}$ (Glycyrrhizinyl)-30 $\alpha$-Lysine.

\section{Purification of A-kinase from Ehrlich ascites tumor cells}

To purify A-kinase in the $0.35 \mathrm{M} \mathrm{KCl} \mathrm{extract} \mathrm{of} \mathrm{Ehrlich} \mathrm{ascites} \mathrm{tumor} \mathrm{cells,} \mathrm{the} \mathrm{extract}$ was applied on a column of DEAE-cellulose, equilibrated previously with $20 \mathrm{mM}$ Tris- $\mathrm{HCl}$ ( $\mathrm{pH}$ 7.6) containing $2 \mathrm{mM}$ dithiothreitol, $1 \mathrm{mM}$ phenylmethyl-sulfonyl fluoride (PMSF), 0.2 $\mathrm{M} \mathrm{NaCl}$ and $10 \%$ glycerol. A-kinase was eluted step-wise from the column with $0.5 \mathrm{M}$ $\mathrm{NaCl}$. A-kinase in the DEAE-cellulose was further purified by gel filtration on Sephacryl S300 and phospho-cellulose column chromatography, successively. Finally, the partially purified A-kinase (phospho-cellulose fraction) was purified by Mono Q column chromatography (high-performance liquid chromatography, HPLC), as previously reported (Shamsa et al. 1991). The purified A-kinase was assayed in the presence of $2 \mu \mathrm{M} \mathrm{cAMP}$ using whole histone (type II-A) of calf thymus or the indicated histones (calf thymus and rat liver) as a phosphate acceptor, as previously reported (Shamsa et al. 1991; Ohtsuki et al. 1992).

Sodium dodecylsulfate polyacrylamide gel electrophoresis (SDS-PAGE) and autoradiography

The ${ }^{32} \mathrm{P}$-labeled polypeptides in the crude and purified histone fractions were analyzed by SDS-PAGE after incubation of the fractions with purified A-kinase and $\left[\gamma^{-32} \mathrm{P}\right]$ ATP in the presence or absence of either GL or oGA, as previously reported (Ishikawa et al. 1990; Shamsa et al. 1991; Ohtsuki et al. 1992). After electrophoresis, the ${ }^{32} \mathrm{P}-$ labeled polypeptides on the gel were detected by exposure (approximately $6 \mathrm{hr}$ at $-80^{\circ} \mathrm{C}$ ) to $\mathrm{x}$-ray film (Fuji-aif RX, Tokyo). 


\section{Results ANd Discussion}

The stimulatory effects of $G L$ and $o G A$ on the phosphorylation of histones by A-kinase in vitro

As previously reported (Shamsa et al. 1991; Ohtsuki et al. 1992), A-kinase highly phosphorylated histones (H2A, H2B, H3 and $\mathrm{H} 4)$ when whole histone (type II-A) of calf thymus was incubated with purified A-kinase and $\left[\gamma^{-32} \mathrm{P}\right] \mathrm{ATP}$ in the absence of GL or oGA (lane 2, Fig. 2). Under the experimental conditions, the kinase did not phosphorylate histone H1. Phosphorylation of histones H2A, H2B and H3 by the kinase was highly stimulated by GL and oGA. The highest stimulation [approximately 4-fold as compared with the absence of the drugs] was obtained at $20 \mu \mathrm{M}$ oGA (lane 4, Fig. 2). $40 \mu \mathrm{M}$ oGA inhibited selectively phosphorylation of histones $\mathrm{H} 2 \mathrm{~A}$ and $\mathrm{H} 2 \mathrm{~B}$, but histone $\mathrm{H} 3$ and other polypeptides $(6.8$ $\mathrm{kDa}, 8 \mathrm{kDa}$ and $10 \mathrm{kDa}$ polypeptides) were still phosphorylated (lane 5); at 100 $\mu \mathrm{M}$ oGA (lane 7 ), over $95 \%$ of the A-kinase catalyzed phosphorylation of these polypeptides was inhibited (Fig. 2). Similar dose effects of the drugs were obtained when other crude histone preparations of rat liver were used as phosphate acceptors (results not shown). These observations suggest that (i) phosphorylation of histones by A-kinase is significantly stimulated by GL or oGA at between $10 \mu \mathrm{M}$ and $20 \mu \mathrm{M}$; and (ii) oGA at concentrations above $40 \mu \mathrm{M}$ causes

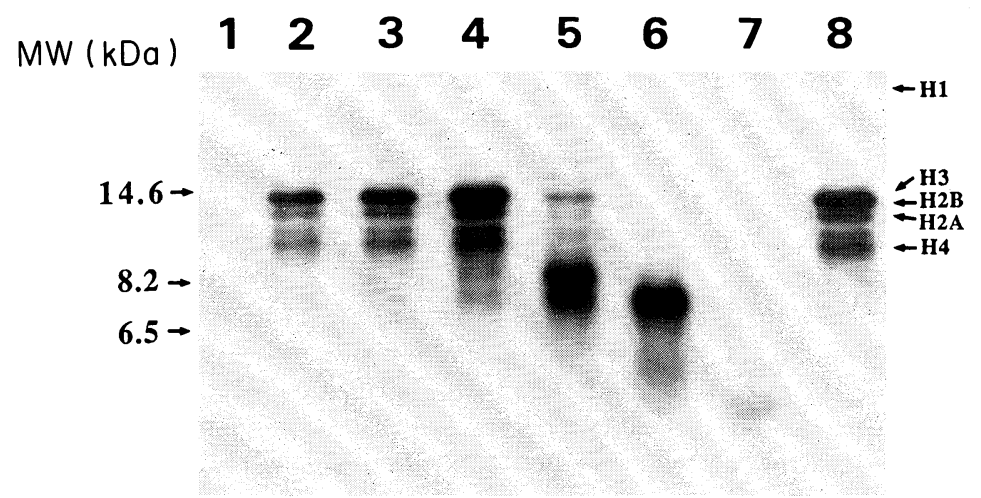

Fig. 2. The effect of GL and oGA on the phosphorylation of whole histone (type II-A) by A-kinase in vitro. To detect histones highly phosphorylated by A-kinase in response to different doses of GL or oGA, whole histone preparation (type II-A) of calf thymus was incubated for $15 \mathrm{~min}$ at $30^{\circ} \mathrm{C}$ with A-kinase and $\left[\gamma^{-32} \mathrm{P}\right]$ ATP in the presence of various concentrations of either GL or oGA. After incubation, the reaction mixtures were analyzed directly by SDS-PAGE followed by autoradiography. Lane 1, A-kinase alone; lane 2, whole histone preparation (type II-A) after incubation with $\left[\gamma^{32} \mathrm{P}\right] \mathrm{ATP}$ and A-kinase in the absence of GL or oGA; and whole histone after incubation with A-kinase and $20 \mu \mathrm{M}\left[\gamma^{32} \mathrm{P}\right] \mathrm{ATP}$ in the presence of oGA [10 $\mu \mathrm{M}$ (lane 3), $20 \mu \mathrm{M}$ (lane 4), $40 \mu \mathrm{M}$ (lane 5), $60 \mu \mathrm{M}$ (lane 6) and $100 \mu \mathrm{M}$ (lane 7)] or 20 $\mu$ M GL (lane 8). 
selective inhibition of the A-kinase catalyzed phosphorylation of histones $\mathrm{H} 2 \mathrm{~A}$ and $\mathrm{H} 2 \mathrm{~B}$, whereas histone $\mathrm{H} 3$ and other polypeptides $(6.8 \mathrm{kDa}, 8 \mathrm{kDa}$ and $10 \mathrm{kDa}$ polypeptides) in the crude histone preparations of calf thymus remain to be detectable as phosphorylated polypeptides. This differential phosphorylation of histones $\mathrm{H} 2 \mathrm{~A}$ and $\mathrm{H} 2 \mathrm{~B}$ versus histone $\mathrm{H} 3$ and other polypeptides $(6.8 \mathrm{kDa}$ and 8 $\mathrm{kDa}$ polypeptides) by A-kinase may be due to differences in binding affinity with GL and oGA during activation and inhibition of their phosphorylation by the kinase in vitro. In addition, the $8 \mathrm{kDa}$ and $10 \mathrm{kDa}$ polypeptides were identified as degraded fragments of histone $\mathrm{H} 2 \mathrm{~A}$ and histone $\mathrm{H} 2 \mathrm{~B}$, respectively, by determination of their partial primary structures (data not shown). However, it was not successful to determine the partial primary structure of the $6.8 \mathrm{kDa}$ polypeptide since the protein yield from the gel was extremely low. Ubiquitin $(8.4 \mathrm{kDa})$, a basic nuclear protein, was also contained in the crude histone preparation, but it was distinguished from the histones since it did not function as a phosphate acceptor for A-kinase.

Separation of the histones H2A-H2B pairs from the crude histone preparations of calf thymus by GL-affinity column chromatography

To further investigate the binding affinity of histones H2A and H2B with GL, they were partially purified from whole histone preparation (type II-A) of calf thymus by GL-affinity column chromatography (HPLC). Following elution with a $\mathrm{KCl}$ gradient, five fractions (peaks I through V, Fig. 3A) were recognized. SDS-PAGE revealed that the peak $\mathrm{V}$ fractions, eluted between $0.6 \mathrm{M}$ and $0.7 \mathrm{M}$ $\mathrm{KCl}$ (Fig. 3A), containing histones $\mathrm{H} 2 \mathrm{~A}$ and $\mathrm{H} 2 \mathrm{~B}$ and a trace amount of $10 \mathrm{kDa}$ polypeptide (lane 6, Fig. 3B), were eluted between $0.5 \mathrm{M}$ and $0.6 \mathrm{M} \mathrm{KCl}$ (peak IV, Fig. 3A), whereas histone H3 (lane 4, Fig. 3B) was eluted between $0.45 \mathrm{M}$ and 0.50 $\mathrm{M} \mathrm{KCl}$ (peak III, Fig. 3A). The $6.8 \mathrm{kDa}$ and $8 \mathrm{kDa}$ polypeptides were detected in the peak II fraction (Fig. 3A), as phosphorylated polypeptides, on separate incubation of these two fractions with A-kinase and $20 \mu \mathrm{M}\left[\gamma^{32} \mathrm{P}\right] \mathrm{ATP}$ in the presence of $60 \mu \mathrm{M} \mathrm{oGA}$, as shown in the result (lane 6) in Fig. 2. No phosphorylated polypeptides were detected in the peak I (breakthrough fraction). The elution profiles (Fig. 3A) of the histones in the crude histone preparation (type II-A) of calf thymus by GL-affinity column chromatography were confirmed using purified histone preparations $(\mathrm{H} 1, \mathrm{H} 2 \mathrm{~A}, \mathrm{H} 2 \mathrm{~B}, \mathrm{H} 3$ and $\mathrm{H} 4)$ under the same experimental conditions. These results suggest that (i) histones H2A and H2B have a similar binding affinity with GL; and (ii) these two histones have a higher affinity to the drug rather than the other histones (H1, H3 and $\mathrm{H} 4)$.

The stimulatory effect of oGA on the selective phosphorylation of histones H2A and $H 2 B$ by $A$-kinase in the presence of $d s D N A$

To determine the dose effect of oGA on the phosphorylation of histones H2A, $\mathrm{H} 2 \mathrm{~B}$ and $\mathrm{H} 3$ by A-kinase, these three purified histones were incubated separately 
A

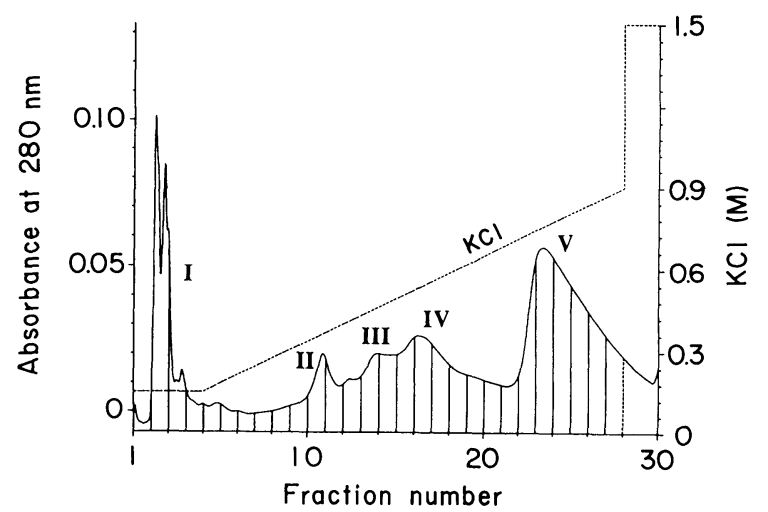

B

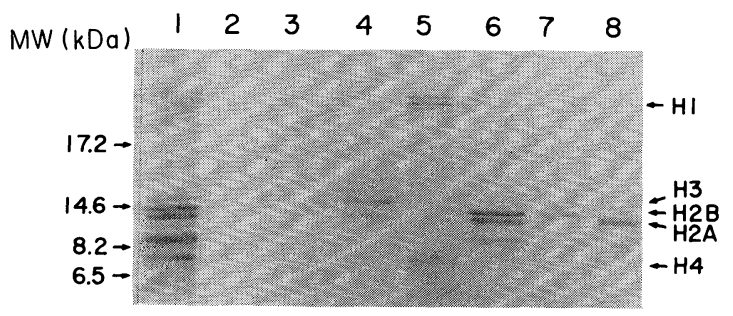

Fig. 3. [A] Separation of histones H2A and H2B from crude whole histone preparation of calf thymus by GL-affinity column chromatography (HPLC). Whole histone preparation (type II-A) was applied on a GL-affinity column (HPLC), equilibrated previously with $20 \mathrm{mM}$ potassium phosphate buffer ( $\mathrm{pH}$ 7.0) containing $0.2 \mathrm{M} \mathrm{KCl}$. Elution was carried out with a linear gradient between $0.2 \mathrm{M}$ and $0.8 \mathrm{M} \mathrm{KCl}$, and fractions $(1.0 \mathrm{ml})$ were collected. Absorbance at $280 \mathrm{~nm}(-)$. [B] Polypeptides of the indicated peak fractions (I through $\mathrm{V}$ in $[\mathrm{A}]$ ) were analyzed by SDS-PAGE, and were stained with Coomassie brilliant blue R-250. Lane 1, whole histone preparation (type II-A); lane 2, peak I (breakthrough fraction); lane 3, peak II; lane 4, peak III; lane 5, peak IV; lane 6, peak V; and purified calf thymus histones H2B (lane 7) and H2A (lane 8).

with A-kinase and $20 \mu \mathrm{M}\left[\boldsymbol{\gamma}^{-32} \mathrm{P}\right] \mathrm{ATP}$ in the presence of various concentrations of oGA. It was found that (i) phosphorylation of histones $\mathrm{H} 2 \mathrm{~A}$ and $\mathrm{H} 2 \mathrm{~B}$ was stimulated about 4-fold by $20 \mu \mathrm{M}$ oGA; and (ii) a similar stimulation was observed with histone $\mathrm{H} 3$ in the presence of $30 \mu \mathrm{M}$ oGA was (Fig. $4 \mathrm{~B}$ ), but a higher concentration (about $200 \mu \mathrm{M}$ ) of oGA was required to inhibit completely phosphorylation of histone $\mathrm{H} 3$ by the kinase. Interestingly, histones $\mathrm{H} 2 \mathrm{~A}$ and $\mathrm{H} 2 \mathrm{~B}$ were phosphorylated selectively by A-kinase when whole histone (type II-A) of calf thymus was incubated with the kinase and $20 \mu \mathrm{M}\left[\gamma^{-32} \mathrm{P}\right] \mathrm{ATP}$ in the presence of both dsDNA (30 $\mu \mathrm{g})$ and $20 \mu \mathrm{M}$ oGA (lane 5, Fig. 5). Similar results were obtained when histone mixtures ( $\mathrm{H} 1, \mathrm{H} 2 \mathrm{~A}, \mathrm{H} 2 \mathrm{~B}, \mathrm{H} 3$ and $\mathrm{H} 4,2 \mu \mathrm{g}$ each) were 
A
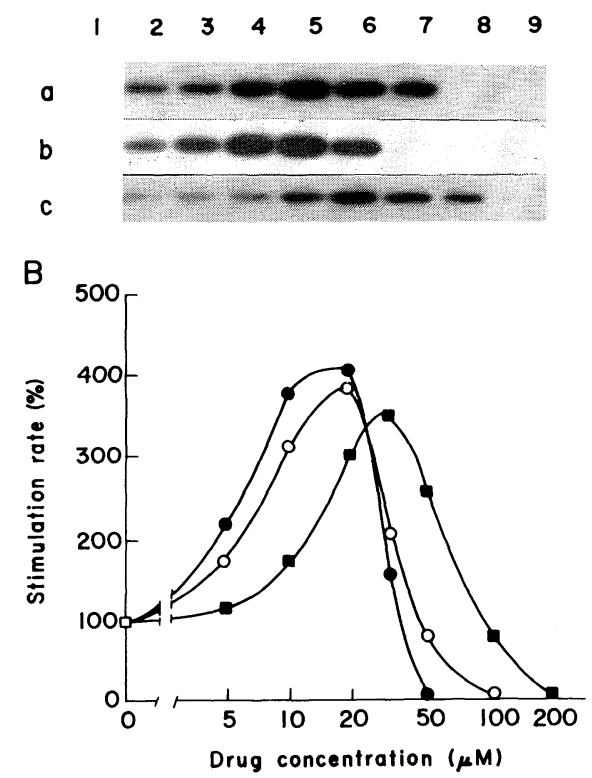

Fig. 4. [A] The dose effects of oGA on the phosphorylation of histones H2A and $\mathrm{H} 2 \mathrm{~B}$ by A-kinase in vitro. To determine the dose effect of oGA on the phosphorylation of histones $\mathrm{H} 2 \mathrm{~A}$ and $\mathrm{H} 2 \mathrm{~B}$ by A-kinase, the purified histones $\left(5 \mu \mathrm{g}\right.$ each) were incubated separately for $15 \mathrm{~min}$ at $30^{\circ} \mathrm{C}$ with the kinase $(0.1$ $\mu \mathrm{g})$ and $20 \mu \mathrm{M}\left[\gamma^{-32} \mathrm{P}\right] \mathrm{ATP}$ in the presence of various concentrations of oGA, and the directly analyzed by SDS-PAGE followed by autoradiography. Purified histone H2A (a), histone H2B (b) and histone H3 (c) were incubated separately with A-kinase and $20 \mu \mathrm{M}\left[\boldsymbol{\gamma}^{-32} \mathrm{P}\right] \mathrm{ATP}$ in the presence (lanes 3 through 10) or absence (lane 2) of oGA [5 $\mu \mathrm{M}$ oGA (lane 3); $10 \mu \mathrm{M}$ (lane 4); $20 \mu \mathrm{M}$ (lane 5); $30 \mu \mathrm{M}$ (lane 6); $50 \mu \mathrm{M}$ oGA (lane 7); $100 \mu \mathrm{M}$ oGA (lane 8); and $200 \mu \mathrm{M}$ oGA (lane 9)]; and A-kinase alone (lane 1). [B] Comparison of the stimulatory effects of oGA on the phosphorylation of histones H2A, H2B and $\mathrm{H} 3$ by A-kinase. Each spot on the film (a, b and c, Fig. 3A) was scanned with a densitometer. $100 \%$ represents the degree of phosphorylation of histones $[\mathrm{H} 2 \mathrm{~A}(\mathrm{O}), \mathrm{H} 2 \mathrm{~B}(\bullet)$ and $\mathrm{H} 3(\boldsymbol{v})]$ by A-kinase in the absence of oGA.

incubated with the kinase in the presence of dsDNA (30 $\mu \mathrm{g}$ ) and $20 \mu \mathrm{M}$ oGA or 20 $\mu \mathrm{M}$ GL (data not shown). However, the A-kinase catalyzed phosphorylation of these histones was inhibited significantly by $30 \mu \mathrm{g}$ of dsDNA (lane 7, Fig. 5). These results suggest that histones $\mathrm{H} 2 \mathrm{~A}$ and $\mathrm{H} 2 \mathrm{~B}$ bound to dsDNA are highly phosphorylated by GL- or oGA-stimulated A-kinase. As expected, the DNA binding ability of histones decreased in proportion to the rate of their phosphorylation by A-kinase (data not shown). However, it failed to detect the stimulatory effect of some steroid hormones (cortisone, androgen and estrogen), which have a chemical structure similar to GL, on the A-kinase catalyzed phosphorylation of histones $\mathrm{H} 2 \mathrm{~A}$ and $\mathrm{H} 2 \mathrm{~B}$ in vitro.

It seems likely, therefore, that the GL-induced stimulation of the A-kinase 


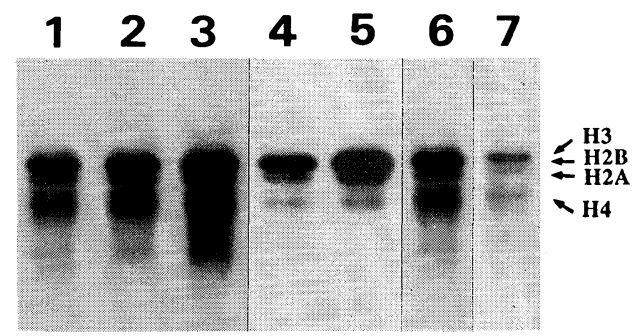

Fig. 5. Selective phosphorylation of histones H2A and H2B by A-kinase in the presence of both dsDNA and oGA. To determine the effect of dsDNA (calf thymus) on the phosphorylation of whole histone preparation (type II-A, 5 $\mu \mathrm{g})$ by A-kinase, the histone preparation was incubated for $20 \mathrm{~min}$ at $30^{\circ} \mathrm{C}$ with A-kinase $(0.1 \mu \mathrm{g})$ and $20 \mu \mathrm{M}\left[\gamma^{-32} \mathrm{P}\right] \mathrm{ATP}$ in the presence or absence of both dsDNA and oGA. Lane 1, whole histone preparation (type II-A) in the absence of oGA; lane 2, whole histone in the presence of $5 \mu \mathrm{M}$ oGA; lane 3 , $20 \mu \mathrm{M}$ oGA; lane 4, $5 \mu \mathrm{M}$ oGA and $30 \mu \mathrm{g}$ of dsDNA; lane $5,20 \mu \mathrm{M}$ oGA and $30 \mu \mathrm{g}$ of dsDNA; lane $6,5 \mu \mathrm{g}$ of dsDNA; and lane 7, $30 \mu \mathrm{g}$ of dsDNA.

catalyzed selective phosphorylation of the two histones $\mathrm{H} 2 \mathrm{~A}-\mathrm{H} 2 \mathrm{~B}$ pairs may be involved in the transcriptional activation of certain genes, because (i) the histones $\mathrm{H} 2 \mathrm{~A}-\mathrm{H} 2 \mathrm{~B}$ pairs may initiate transcription by their temporary ejection from nucleosomes in promoter regions following their specific phosphorylation (Felsenfeld 1992; Grunstein 1992); and (ii) administration of mouse with relatively low doses of GL results in the induction of IFN $\gamma$ gene product (Abe et al. 1982) and the induction of extrathymic T cells in liver (Kimura et al. 1992). Although the biological significance of the GL-induced stimulation of the A-kinase catalyzed phosphorylation of the two histones $\mathrm{H} 2 \mathrm{~A}$ and $\mathrm{H} 2 \mathrm{~B}$ pairs in vitro is unclear at present, a complicated regulatory mechanism at the transcriptional level may be involved in the anti-inflammatory effects of GL and glucocorticoids, which have a similar chemical structure to GL. This speculation is supported by recent reports (Northrop et al. 1992; Nishio et al. 1993) concerning anti-inflammatory mechanisms, which show that a variety of serum proteins, named acute-phase proteins; such as haptoglobin, hemopexin and fibrinogen are induced by antiinflammatory drugs and inflammatory cytokines, such as interleukin-1 (IL-1), interleukin-6 (IL-6) and tumor necrosis factor-alpha (TNF $\alpha$ ). These cytokines ultimately augment the synthesis of acute-phase proteins at the transcriptional lelvel since most their genes harbor a cytokine responsive elements (CREs) in the 5 -flanking regions of these genes and a specific binding of DNA-binding transcriptional factors, such as glucocorticoid hormone receptor (GHR), to the specific elements involved in the initiation of these selected genes (Evans 1988; Burnstein and Cidlowski 1989; Kapiloff et al. 1991) is regulated by serine/threonine protein kinases (Denton et al. 1992). In addition, the anti-inflammatory effect of GL is also mediated by other inhibitions induced by the drug, because the doses above 
$10 \mu \mathrm{M}$ of GL inhibit (i) the A-kinase catalyzed phosphorylation of lipocortin I (an inhibitor of phospholipase A2) in vitro (Ohtsuki et al. 1992), (ii) the CK-II catalyzed phosphorylation of a $100 \mathrm{kDa}$ GL-binding protein, which is crossreacted with anti-glucocorticoid hormone receptor, in vitro (Ohtsuki et al. 1994), and (iii) the activities of both hepatic $\Delta^{\prime}$-5-reductase and 11 $\beta$-hydroxysteroid dehydrogenase in rat (Kojima et al. 1990). However, to understand the biochemical mechanisms involved in the GL-induced biological effects, such as gene activation and cell activation, it is necessary to investigate in detail the transcriptional regulation of selective genes by specific phosphorylation of the histones $\mathrm{H} 2 \mathrm{~A}-\mathrm{H} 2 \mathrm{~B}$ pairs on chromatin by GL-activated A-kinase.

\section{Acknowledgments}

This work was supported in part by grants from the Ministry of Education, Science and Culture of Japan (1993) and the Foundation of Japan Private School Association (1993). We thank Dr. M. Oh-Ishi for helpful discussions.

\section{References}

1) Abe, N., Ebina, T. \& Ishida, N. (1982) Interferon induction by glycyrrhizin and glycyrrhetinic acid in mice. Microbiol. Immunol., 26, 535-539.

2) Burnstein, K.L. \& Cidlowski, J.A. (1989) Regulation of gene expression by glucocorticoids. Annu. Rev. Physiol., 51, 683-699.

3) Dargan, D.J. \& Subak-Sharpe, J.H. (1985) The anti-viral activity against herpes simplex virus of the triterpenoid compounds: Carenoxolone sodium and cycloxone sodium. J. Gen. Viol., 66, 1771-1784.

4) Denton, R.R., Koszewski, N.J. \& Notides, A.C. (1992) Esterogen receptor phosphorylation. J. Biol. Chem., 267, 7263-7268.

5) Evans, R.M. (1988) The steroid and thyroid hormone receptor superfamily. Science, 240, 889-895.

6) Felsenfeld, G. (1992) Chromatin as an essential part of the transcriptional mechanism. Nature, 355, 219-224.

7) Finney, R.S.H. \& Somers, G.D. (1959) The anti-inflammatory activity of glycyrrhetinic acid and its derivatives. J. Pharmacol., 10, 613-620.

8) Grunstein, M. (1992) Histones as regulators of genes. In: Scientific American, Scientific American Inc., New York, pp. 40-47.

9) Ishikawa, A., Kanamaru, R., Wakui, A., Kanno, S. \& Ohtsuki, K. (1990) Characterization of glycyrrhizin-binding protein kinases from the crude membrane fraction of rat liver. Biochem. Biophys. Res. Commun., 167, 876-882.

10) Ito, M., Nakashima, H., Baba, M., Pauwels, R., Clercq, E., Shigeta, S. \& Yamamoto, N. (1987) Inhibitory effect of glycyrrhizin on the in vitro infectivity and cytopathic activity of human immunodeficiency virus [HIV (HTLV-III/LAV)]. Antiviral Res., 7, 127-137.

11) Kapiloff, M.S., Farkash, Y., Weger, M. \& Rosefeld, M.G. (1991) Variable effects of phosphorylation of Pit-1 dictated by the DNA response elements. Science, 253, 786789.

12) Kimura, M., Watanabe, H. \& Abo, T. (1992) Selective activation of extrathymic T cells in the liver by glycyrrhizin. Biotherapy, 5, 167-176.

13) Kojima, M., Satoh, K., Gomibuchi, T., Itoh, N., Kin, S., Fukuchi, S. \& Miyachi, Y. (1990) The inhibitory effects of glycyrrhizin and glycyrrhetinic acid on the metabolism of cortisol and prednisolone. Folia Endocrinol., 66, 584-596. (in Japanese) 
14) Nakamura, K., Hashimoto, T. \& Kato, Y. (1990) Tresyl-activated support for highperformance affinity chromatography. J. Chromatogr., 510, 101-113.

15) Nishio, Y., Isshiki, H., Kishimoto, T. \& Akira, S. (1993) A nuclear factor for interleukin-6 expression (NF-IF6) and the glucocorticoid receptor synergistically activate transcription of the rat al-acid glycoprotein gene via direct protein-protein interaction. Mol. Cell. Biol., 13, 1854-1862.

16) Northrop, J.P., Crabtree, G.R. \& Mattila, P.S. (1992) Negative regulation of interleukin 2 transcription by the glucocorticoid receptor. J. Exp. Med., 175, 1235-1245.

17) Ohtsuki, K., Oh-Ishi, M. \& Nagata, Y. (1992) The stimulatory and inhibitory effects of glycyrrhizin and a glycyrrhetinic acid derivative on phosphorylation of lipocortin I by A-kinase in vitro. Biochem. Internatl., 28, 1045-1053.

18) Ohtsuki, K., Oh-Ishi, M., Karino, A., Kanekatsu, M. \& Shamsa, F. (1994) Purification and characterization of a $100 \mathrm{kDa}$ glycyrrhizin (GL)-binding protein (gp100) as an effective phosphate acceptor for CK-II and the effect of GL on the phosphorylation of gp100 by CK-II in vitro. Biochem. Biophys. Res. Commun., 198, 1090-1098.

19) Pompei, R., Flore, O., Marccialis, M.A., Pani, A. \& Loddo, B. (1979) Glycyrrhizic acid inhibits virus growth and inactivates virus particles. Nature, 281, 689-690.

20) Shamsa, F., Nagata, N., Oh-Ishi, M. \& Ohtsuki, K. (1991) The in vitro effects of glycyrrhizin and the derivatives of glycyrrhetinic acid on the activity of cAMPdependent protein kinase and phosphorylation of cellular polypeptides by the kinase from Ehrlich ascites tumor cells. Tohoku J. Exp. Med., 165, 305-318.

21) Strickland, W.N., Strickland, M.S., Groot, P.C. \& Van Holt, C. (1980) The primary structure of histone H2A from the sperm cell of the sea urchin Parechinus augulous. Eur. J. Biochem., 109, 151-158. 